\title{
ON THE NOTION OF A RULE
}

\author{
Thomas Olshewsky \\ University of Kentucky
}

In his "On the Notion 'Rule of Grammar", Noam Chomsky gives an exposition of the need for a precise formulation of a rule of grammar. In so doing, he cautions us not to take too readily a generative grammar as a model for the speaker or the hearer of a language (Chomsky, 1961, Note 16). That caution has not been widely heeded, not even by Chomsky himself. His tone in Language and Mind, already presaged in Aspects, is quite different. While noting there that other factors are involved in language performance, he maintains that language acquisition is an internalization of a system of rules and that language performance is their employment (Chomsky, 1968, p. 23). One might expect this claim to invite an exploration of the conceptual relationship between rules of language and patterns of verbal behavior. Rather, many psychologists bave taken Chomsky's later thesis as a given foundation for inquiry, not as a problem to be dealt with (cf. McNeill, 1970; Miller and Isard, 1963; Saporta, 1967). I hope through explorations of the notion of a rule to reinstitute Chomsky's earlier caution.

Based on Chomsky's thesis, linguists, psychologists and philosophers alike have found a renewal for the contention that verbal behavior in particular and human behavior in general is rule-governed behavior. John Searle (1969) takes as the thesis for his book, "Speaking a language is engaging in a rule-governed form of behavior". G. A. Miller (1963) notes, "The question remains open whether a descriptive science, such as psychology aspires to be, can incorporate systems of rules into a framework provided by the more traditional form of scientific laws". I find the orientation inviting, but for it to become a workable one there is the need to explore not only the relation of language to speaking, but also to understand the notion of rule-governed behavior in these contexts. The problems have not gone unrecognized (cf, Quine, 1970), but positive ways of dealing with them remain to be devised. In exploring the notion of a rule, I will expose some questions I find relevant to the notion of a rule in the psycholinguistic enterprise, and some theses that may give some direction for dealing with the problems.

I

One way of getting at the notion of a rule is to characterize how rules operate in different contexts of action and inquiry. ${ }^{*}$ A first general characterization is whatrules are *

Henley (1969) suggested the starting points that I have taken, but they have undergone considerable reworking in my hands. He is in no way responsible for-and probably would not agree with-much of the outcome. The work of Gumb (1973) is also pertinent to this study, but I have not yet had the opportunity to study it. 
context-dependent. A rule is always a rule of something, a rule of chess, a rule of etiquette, ete., and that something determines the context in which the rule is operative. A rule need not be limited to a single context, but for it to be a rule, it must operate in some context. This gives us our first thesis:

T-1: Rules are necessarily context-dependent, and it is always possible to specify the rule-context whenever "rule" is properly used.

A part of understanding a rule, then, is to understand the context in which it operates.

Not only are rules context-dependent, but they also serve different roles in relation to their contexts. This gives us our second thesis:

T-2: Rules operate according to distinguishable and determinable roles within any given context.

The distinction of roles requires a typology and any one offered will inevitably be subject to debate. The categories that follow give at least a workable typology, and will facilitate our exploration of the notion of a rule in psycholinguistics: A generalization role is one in which the rule serves to formulate regularities of the context; e.g., rules of safe driving or rules of proper diet. A regulative role is one in which the rule serves to regulate operations within a context, or bring order to a context, e.g., rules of the road or rules of table etiquette. A constitutive role is one in which the rule serves to establish a context or define it; e.g. , rules of chess or of some other game. This logically leaves the way open for a single rule to play different roles in different contexts. Indeed, it may be possible for a single rule to play different roles in the same context, but this requires further exploration.

Regulative roles for rules presuppose the context as given, and thus the rules are dependent upon the context. For generalization roles and constitutive roles the existence of contexts and rules are co-dependent. Regulative roles are ordinarily developed upon conventional foundations, while generalization roles derive from knowledge of the nature of the context, ordinarily based upon experience. Here we have an echo of the Humean categories for knowledge which lie at the base of standard interpretations of the analytic/synthetic distinction. Were constitutive roles also construed as conventional, we would have a neat set of differentiae by which no rule could unambigously serve more than one of the three roles in any given context. So long as we limit ourselves to games for paradigms, this seems a safe move. The question is whether or not the Kantian manner of treating constitutive rules is an appropriate one. To ask waht constitutes human experience, or even mathematics and natural science, is not like asking what constitutes chess or bridge or baseball. The answers cannot be derived from conventions, nor generalized from experiences, but must be found in an exposition of the presupposed foundations for any possible operation within the context. It is against the backdrop of this expanded conception of a constitutive role that controversies 
over nativism and "innate ideas", as well as those over linguistic universals, begin to make sense. With such a conception of constitutive roles, we can at least understand the claim that a linguistic model may serve as a psychological one. The claim is that the rules which have a generalization role in a theory of language will also have a constitutive role in its use.

All three kinds of role for rules have both descriptive and normative (prescriptive?) force. How these forces relate to one another and to particular roles for rules in context seems a worthwhile topic for study unto itself. Perhaps descriptive force dominates in the generalization role, but normative force dominates in the constitutive one. Certainly there is a normative force to the formulation of regulative rules as well as to their employment. Whatever the details, such a study based on these starting points would facilitate Miller's concern with the status of rule-governed behavior in science, without getting hung up on the notions of descriptive vs. prescriptive meanings for rules.

Lest we too readily assimilate rules to laws, it is important to note that rules can always be broken. So long as we deal with the notion of a law in a legislative context, it can be assimilated to the notion of a rule. Statutory laws are regulative rules and constitutional laws (presumably) are constitutive rules. To break a regulative rule is inappropriate within the rule-context, but to break a constitutive rule does violence to the definition of the context itself. Action breaking a constitutive rule will be ineffectual or impossible within the rulecontext, or it will be judged not in that context at all. Moving the king more than one space in a single move is ineffectual, trumping with a king is impossible, and stacking a king on top of a rook may be a part of some game, but clearly not a game of chess. Not all constitutive violations are so neat as these examples, and not all contexts are so neat as a wellconstituted game, as constitutional law will so readily testify. More difficult examples may well strain $\mathrm{T}-1$.

The relation of generalization rules to natural laws is more difficult. Rules of proper diet, for instance, are based upon bio-chemical, physiological and other natural laws. In this role, the notion of a rule comes closest to the laws of the "descriptive" sciences. But in this role, rules are derivative from laws and not equatible with them. These rules can be violated without violating the relevant laws; indeed, in the very violation of the rules, the relevant laws are given negative verification. They are not reducible to the laws, however, since they involve value considerations not entailed by the laws themselves. For rules of proper diet you need the value consideration of good health; for the rules of safe driving you need the value consideration of personal safety. But it seem plausible that generalization rules can be analyzed into the relevant natural laws, together with the relevant value considerations. If so, given the claims of recent linguistics and psycholinguistics, this cannot be the notion of a rule we are seeking. 
Wittgenstein and his followers have made much of treating sub-classes of languages on an analogy to rules of games. While this may prove satisfactory for certain aspects of semantic concern, it serves as a singularly inappropriate model for a language as a whole. Games involve a conscious entering into, whereas a language provides a basis for entering in. Far from being the result of convention, language is presupposed by virtually all conventional engagements. For rules of games, constitutive rules as well as regulative rules are made definite by conventions for specified purposes. The rules of Hoyle as well as the rules of Goren for bridge came into being by human decision, whether explicit or implicit, singular or collective. Linguistic structures are constituted by physiological and psychological as well as social conditions. The French Academy may set forth rules, but these are regulative rather than constitutive. Whether positive merit nativism may have (and I think it has little or none), its negative thrust is that the positivistic options of empirical generalization or conventional definition are inadequate. Rules of languages are not like rules of games.

While the analogy is thus defective, it points to another problem. However limited, the analogue between rules of a game (say, bridge) and rules of a language (say, English) would lead one to expect a compaxable analogue on the more general level. Yet, we are never inclined to speak of rules of Game in the way so many readily speak of rules of Language. If, indeed, rules are context dependent, we fail to find a context called "Game" that is defined by any set of rules. What is there to lead us to suppose that there is a context called "Language" that serves as a context for rules of language? Such a context is neither present for observing rule-governed behavior nor for engaging in it. T-1 seems to make the notion of a rule of Language an anomalous one.

Thus fax, we have spoken only about rules of language, not about rules for speaking. The shift from of to for seems not an insignificant one. Where the former relates rules to a context, the latter relates rules to goal-directed activity. This invites an analogy of rules to tools. The bammer is a tool of carpentry, but is a tool for doing carpentry work. Here, we must not be hasty to assimilate rule-governed behavior to goal-directed activity, or to equate rules with tools. There are hazards enough with such moves as we shall see presently. Rather, the point that I would make here is that the roles of rules in language are different in kind from the roles of rules in speaking-indeed, even the senses of "in" here seem different. Adequate explication of the nature and relation of these roles is a condition for meeting the concerns with which we began.

We might hope for an explication of rules for speaking in speech-act analyses such as those of Seaxle (1969), but rules for speech-acts are not equatable with rules for speaking. In semiotic terms, speech-act analyses are pragmatic. They are concerned with what the 
speaker can do in and through the act of speaking. Phonetic, syntactic and semantic rules may provide the speaker with the equipment for that doing in and through. So far the rules as tools treatment seems plausible. Yet, there is the act of speaking to be considered as well. The doing of the speaking itself cannot so plausibly be treated as a goal-directed activity as doing something in and through that act. Some discussions have been hopelessly misleading on this point. Fodor, for example, maintains that a child "applies" or "employs" linguistic rules to perceptual input (Fodor, $1966, p .117$ ). Such means-ends characterizations which are appropriate to goal-directed activity seem singularly inappropriate for locutionary acts, while quite satisfactory for illocutionary and perlocutionary ones.

For linguistics, generalization roles seem appropriate for consideration of rules of a language. For psychology, regulative and constitutive roles seem appropriate for consideration of rules for speaking. Attempts to conflate generalization roles with constitutive roles are attempts to provide a bxidge between linguistics and psychology. They are also the basis for conceptual confusion over the nature of a theory of language. Insofar as one regards the rules in generalization roles, the conception of a hypothetico-deductive model is appropriate, similar to an empirical science. Insofar as one regards the rules in constitutive roles, the conception of an axiomatic system is appropriate, similar to a formal science. Controversies over which conception is appropriate to a theory of language have been generated out of the attempt to have the theory both ways. This is not to say that we cannot have it both ways, but how this could be so remains a conceptual problem.

These preliminary explorations of problems with contexts and roles for rules leave us with at least two questions relevant to our concerms:

Q-1: How closely knit a family is the set of concepts expressed by "rule"? (e.g. , rule of a game, rule of thumb, rule of inference; or rule of grammar, rule of linguistic acquisition, rule of action)

Q-2: How, if at all, do rules of language function as rules for speaking? To deal with such questions we need to make further explorations into the concept of rulegoverned behavior, and into issues related to the language-speaking distinction relevant to a theory of language.

\section{II}

In his discussion of rules, Wittgenstein distinguishes between a process being in accordance with a rule and a process involving a rule (Wittgenstein, 1958, p. 14). His example is the number series " $1,4,9,16, \ldots "$. Arriving at the next number in the series may be in accordance with the rule of squaring, but it need not involve that rule. I might, for instance, see that by adding 3 to 1 , I get $4 ; 5$ to 4 , I get $9 ; 7$ to 9 , I get 16 ; so that 
by adding 9 to 16 , I will get 25. This rule works as well for generating the series as does the squaring rule. That they have proved to be logically equivalent only assures me that they work equally well. Clearly, my calculations using the one rule will be a different kind of operation from what it would be with the other, even though my activity in employing either, or another, or none (on the implausible basis of persistent lucky guesses) would appropriately be characterized as being in accordance with both. In like manner, it is plausible for me to speak in accordance with the rules of a language without those rules being involved in that speaking. If our sense of rule-governed behavior is to be behavior in accordance with certain rules, then we would have a clear, but innocuous sense of how to answer Q-2. It would just as clearly be inadequate to the concerns of the relation of linguistic theory to psychological inquiry. By the same token it would reconcile rule-governed behavior to natural laws since any regularity could be counted as in accordance with a rule.

A process involves a rule, according to Wittgenstein, if "the symbol of the rule forms part of the calculation". But this suggests that the process under consideration is a goaldirected activity in which rules are tools, in which the rules of language are means to the end of a process of speaking. We can hardly say that a speaker uses his language to speak (rather, we say he speaks in his native language). The alien may indeed use his knowledge of the rules of a foreign language as a means to speaking it, but the mark if the native is that, insofar as he is competent in speaking, this means/ends distinction is absent from his process of speaking-that it is not a calculation. Where "according to a rule" proved too weak for rule-governed behavior, this sense of "involving a rule" proves too strong.

The notion of following a rule seems trapped ambiguously between these two. Suppose the speaker is following a rule without knowing it. This strains our metaphor of following, and leaves us with nothing more than acting in accordance with a rule. On the other hand, to explicitly know he is following a rule puts us back with goal-directed activity, this time with the rule as analogous to a guide toward a goal. The guide analogy fails on the same sorts of counts as the tool analogy. If we appeal to some sort of tacit knowledge about following a rule, we have made no gain until the character of both the knowing and the following are sorted out. Thus, in seeking an answer to our initial questions, we have picked up another:

Q-3: What sense of "involving a rule" or "following a rule" is implied by "rulegoverned behavior" ?

There is a sense in which this whole manner of treating the problem misses the mark. Rules that serve as tools or as guides in rule-governed behavior are ordinarily regulative rules, not constitutive ones. They serve to make the activity more effective or more efficient or more appropriate, but they do not serve to make the activity what it is as an activity. The 
constitutive role in relation to activity within its context is usually one of setting limits on activity within the context, rather than providing guidance for action. This provides a basis for a new tact with a new thesis:

T-1: Rules account for opposition by setting limits for action.

T-3 presupposes that rules are formulations in action rather than features of reality. The features of reality are the oppositions confronted in action. It further presupposes that the formulations will, initially at least, be negative, setting limits on action within the context of that rule-governed behavior. Thus the rules govern the behavior by restricting its scope and character.

A comparison to moral contexts may be helpful. Moral theories are usually divided into teleological and deontologieal theories. The former are construed in terms of ends or goals, the latter in terms of rules or maxims. Teleological theories invite formulation of obligations in terms of what one ought to do; deontological theories invite formulation of oblications in terms of what one ought not to do. It is in this way that rule-governed behavior has a quasi-moral or deontological character. Rules tell us what we may not do.

This understanding of rule-governed behavior runs counter to the roles rules play in the formal sciences. There, the rules are both constitutive and teleological. They both constitute the structure of the system and serve as explicit means for new formulations, by formation or transformation. However, insofar as these systems are construed logicistically, the rule contexts are determined conventionally against the backdrop of purposes beyond the system (cp. Carnap, 1950). On an intuitionalist understanding, the rule contexts are determined by the limits of reality, giving again a deontological base, expressed negatively as limits. However one construes the foundations of mathematics, these alternatives reveal different understandings of the constitutive role for rules. Either the constitutive constraints are formulated teleologically by convention, or they are confronted deontologically as limits to action. Whatever one's metaphysical commitments, the former interpretation has many heuristic values for mathematics. So long as we claim to be working with natural languages, the former is clearly implausible both theoretically and practically for studies of language and of speaking.

With T-3 as a starting point, we have a basis for understanding rule-governed behavior in the weakest possible sense:

Rule-governed behavior ${ }_{1}=$ Df. Habituated activity within a delimited context, where the habituation is determined negatively by these limits, but can be described as being in accordance with a set of rules that make the limits definite. On this interpretation, it is possible for different sets of rules, logically equivalent, to define the context for action. It is also possible for many patterns of action to be governed 
by these rules, without these actions ever confronting the limits of the context for which the rules give an accounting. Thus, it is possible for actions to be constrained by limits without involving a rule. This makes the non-smoker "governed" in his actions by the regulation of a no-smoking rule, since the act of smoking would be possible for him independent of the context, and the rules of the context would prohibit that action. Still, while we might be willing to concede that he was governed by the rule in this weak sense, we would find it odd to say that he was obeying it, and ludicrous to say that he was following it.

In the light of such considerations as these, Saporta, 1967, p. 22) rejects such a weak sense of rule-governed behaviox. He maintains that "in any case where the simplest simulation of the organism requires computations that appeal to the rule, it follows that the organism whose behavior is simulated must know the rule." This would at least be a plausible claim, were a given set of rules uniquely appropriate to a given context. But as we saw in the example of the squaring and additive rules, this is not the case. To simulate the processes required to develop that number series does require computations that appeal to a rule, but not to a uniquely determined one. If the psycholinguist finds his own rules uniquely determined, it is because they are so determined by the theoretical system in which he operates, not by the activity context in which his subject operates. This throws us back to the problems of inferring from the generalization role of linguistic rules to the constitutive and regulative roles of rule-governed behavior in speaking. Even if we concluded on some ground or another that the squaring rule is theoretically preferable, the subject would not have to know it in any sense of "know" to carry out the activity required. That he would have to know some rule in some sense seems to be required for treating patterned behavior as rule-governed, and this does require a stronger sense of rule-governed behavior than our first, weak sense.

A stronger sense of rule-governed behavior is one in which the organism knows where the limits are, though he may not know what the limits are.

Rule-governed behavior ${ }_{2}=$ Df. Habituated activity determined negatively by the

limits of the context and deriving its patterns from confrontation with those limits. The limits are learned by breaking the rules in the sense of activity exceeding the limits of the context, and thus proving in a variety of possible ways unsuccessful action for that context. This need not involve the formulation or "internalization" of rules for the context, but only an accommodation of action to its limits. Such a trial and basis for habituating action to the limits of a context is for a variety of reasons both inefficient and inadequate. But an individual's society cooperates with him in the development of his action patterns, both by positive reinforcement and by derivative negative reinforcement. By such social constraints, the organism may be habituated to certain patterns of action in accommodation to dexived 
limits imposed by his society. Such cooperation would not require the organism to know the ultimate limits of the context, much less rules that govern action in relation to them; but insofar as it were intentional, such cooperation would require his society to know what the limits were and some set of rules that would account for them.

Neither of the senses offered so far gives us a basis for talk about internalizing, knowing, employing or applying rules. For this, we need a yet stronger sense.

Rule-governed behavior ${ }_{3}=\mathrm{Df}$. Habituated activity understood by the actor as in a context determined by rules accounting for the limits of that context. Such rules may be employed by the actor as guides for further activity.

This is the first sense which seems adequate to the inquiries of linguistics, mathematics and computer science; it is strong enough to support concerns with explanation, prediction and inference; it is too strong, as we have seen, to impute to the speaker/hearer as a condition for his competence, and it is stronger than necessary for a society to acculturate its members to patterns of actions within rule-ordered contexts. Because models for languages in linguistics, mathematics and computer science presuppose something like this understanding of rule-governed behavior, they are clearly inappropriate for models for psychological development and performance. None of the senses offered give an adequate understanding of rule-governed activity for the speaker/hearer; and if we had such, we would still need an account of how the organism moves in his development from reaction to action to rule-formation to rule-employment. In terms of $\mathrm{T}-3$, this latter question becomes:

Q-4: How does an organism develop in its operations from confrontation with limits to formulating limits as rules for use in subsequent activity?

III

While the nativist would agree that there is development, he would maintain that the rules themselves are not the creations of human action, but are in some sense built into the organism from the outset. This discussion based on T-3 is thus clearly anti-nativistic. This does not imply that it is therefore, as so many would infer, behavioristic. This exploration has throughout presupposed that action is intentional action. The employment of "behavior" in psychology is usually a slippery one, since it claims honorifically to be empirical, and yet serves to refer to action interpreted as intentional. For most purposes this is harmless enough, but will not do when the notion of behavior itself is in question. Philosophers, working on the concept of action, usually distinguish action from behavior, only to be left wondering how to understand intention, and how to relate the notion of action to that of behavior. One patent move is to reduce action categories to behavior categories. Such attempts inevitably resort to some dispositional concepts ("belief", "attitude", or more generally "habits", 
"propensities") as reduction devices. Work with reduction sentences has shown that dispositions require ana analysis in terms of contrary-to-fact conditionals, and that these conditionals cannot be completely reduced to perational considerations (cp. Hempel, 1965 ).

T-4: Reduction of dispositional statements to observation statements is systematically impossible.

With such a conclusion, it should become clear that the "behavior" spoken of in "rule-governed behavior" is not strictly speaking observational, but requires interpretation as intentional action or dispositions to action.

I am inclined to maintain a stronger thesis than $\mathrm{T}-4$; namely, that dispositions can only be understood as potentials for actualizations of some ends, and must therefore be dealt with in a teleological framework of explanation. Even this stronger version would not preclude the development of intentions from dispositions from events, as $Q-4$ seems to call for, but it does expose something of the conceptual complexities involved. To deny that such development takes place would require that we posit either dispositions or intentions as starting-points. Perhaps this is what is embedded in the nativist claim, but that too requires some explanation. In the end, I think we need an adequate understanding of intentional action to get at the notion of a rule in rule-governed activity. To say that intentional action is goaldirected action is inadequate. Goal-direction is a sufficient condition for intention, but not a necessary one. It is quite appropriate to call an action intentional even when it is not done "on purpose." Indeed, it was just at this point that we found our analysis of "governed" inadequate. For a rule to be "involved" does not require it to be a tool or a guide to activity any more than intention requires purpose. The sense in which "rule-governed" activity involves a rule, but not as a tool fox calculation, is just the sense in which activity is intentional, but not goal-directed. It is in this as yet inadequately explored range of meaning that the sense of a notion of a rule relevant to concerns in psychology of language lies.

IV

So far, questions and theses regarding rule-governed behavior have been exposed by treating "rule", "governed" and "behavior" in turn. Another tact of exposition might be to examine other sets of categories relevant to psycholinguistics with which rules and action seem to have some affinities. There is some temptation to draw analogies along the lines of rule/action $=$ structure $/$ function $=$ competence $/$ performance $=$ explanation/observation. The extent to which such equations of the relations of categories can be run would make an interesting comceptual exploration in itself. We can explore the matter here only so far as the various sets of categories shed some light on the notion of a rule. 
Structures serve as a basis for function as rules serve as a basis for actions. The statement is patently false, but invites further exploration. First, kinds of structures must be distinguished. Social, linguistic and physical structures differ in kind from one another precisely with reference to the role played by rules. The structures of language and society are describable in terms of rules for the formulation of structures and of rules for the operation of functions within those structures. Physical structures by contrast can be described without recourse to rules, and it makes no sense to speak of the rules of formation for physical structures. Physical functions are described in terms of laws, not rules. How like laws rules may be and to what extent the latter can be reduced to the former are salient problems in philosophy of science, and on them turn many of the questions about how social and behavioral sciences are related to physical and biological sciences. But laws are not rules. An analysis of how laws differ from rules might be very revealing for how concepts of structure and function and the relation between structure and function differ between a physical and a social context.

In a quite different manner, linguistic structures differ from social structures. In the sense that formation and function rules for social constitutions can be changed by human decision and action, they are conventional. On a TG analysis, linguistic rules are not of the same sort. The prevalent thesis is that they are built in; built into the organism for base structure and into the language for transformations to surface structure. The senses of structure here seem amenable neither to the physical model nor to the social one. Language structures are analogous to physical structures except that they require rules for their description. Speaking functions are analogous to social functions except that their constitutive foundations are not clearly conventional. Linguistic rules hang in conceptual discomfort between physical laws and social norms. Just as their status relative to the formal/empirical divide is problematic, so is it, relative to the physical/social divide. However the analogue between rules/action and structure/function may work out, the notion of a rule as a psycholinguis tic phenomenon will remain problematic.

There is one clear sense in which structures a re like,rules. Both set limits to function. But, as we have seen, there are rules in and for action as well as action according to rules. Rules, as human formulations, serve as tools as well as limits. As such, they differ from physical structures and from physical laws. As such, they also differ from linguistic rules, at least from that notion of rule that we have been seeking.

Also like rules, competence sets limits to action, and in its relation to performance seems to have a similar role to that of structure in relation to function. The competence/ performance categories also serve as a conceptual bridge between linguistics and psychology. The prevailing analogy between competence/performance and langue/parole is a misleading 
one, however. Competence, unlike structure, is an action category. Competence is a condition for performance in different ways from structure as a condition for function, and from language as a condition for speaking. Competence is teleologically defined in ways (presumably) structure is not. Competence can only be understood in terms of the performance it is the competence for, while structure can be understood independent of function. So too with language and speaking, but in a different way. One speaks a language, but one does not perform a competence. One must surely have competence with a language in order to have the performance of speaking it, but this does not warrant equating the relation of language to speaking with that of competence to performance. Where we can speak of rules of language and rules for speaking and performance, we cannot speak of rules for competence. Another problem with the role of "competence" on psycholinguistic discourse is a systematic ambiguity between its capacity-sense and its ability-sense (the distinction here is a technical one, since "capacity" and "ability" are used interchangeably in most discourse, which facilitates the ambiguity). "Capacity" has a passive connotation and "ability" an active one. Capacities are "built in" to the organism, but abilities are developed. One may have the capacity to speak Language, but he acquires the ability to speak a language, and it is in the acquisition of this ability that he is said to acquire a language. Insofar as competence sets limits in the capacity-sense, it is related to performance just as structure is to function. But this is so just so far as we can say that physiological structure determines the capacity for speaking, and the structures involved here are not linguistic; nor does a notion of rule in any way come into play. While there may be some sense in which the acquisition and employment of abilities for speaking is rule-governed, the sense is not clear, nor is it clear that such psychological rules are of the nature of linguistic ones. An understanding of how the competence/performance categories serve as a bridge between linguistics and psychology, then, requires some sorting out of these issues. Far from illuminating the role of linguistic rules in the act of speaking, the presuppose an understanding of that role.

I noted at the outset $G$. A. Miller's concern with the role of rules in descriptive science. The contrast of descriptive/normative motivated his concern, since it is in the context of the normative that discussion of rules most readily appears. We might equally well ask about the role of rules in an explanatory science. Is "rule-governed behavior" an explanatory term in psycholinguistics to give an account of observed and predicted acts of speaking? This seems a specification of the broader question of analogues between explanation/observation and rules/action. To pursue the matter, we need an additional thesis:

T-5: Explanation influences description and is not reduceable to it.

The thesis is necessary because unenlightened neopositivists and neobehaviorists have continued to maintain a descriptivist view of theories (i.e., that theories are shorthand descrip- 
tions of observations), and this has remained most prevalent in psychology, of all the sciences. The move away from such a view, ironically, has been led by such logical positivists as Carnap (1936) and Hempel (1965) themselves. The latter portion of $\mathrm{T}-5$ is but a corollary to $\mathrm{T}-4$, since analysis of theoretical terms inevitably results in dispositional formulations. The former portion is but a claim that observation statements themselves are theory-laden, and require for their understanding some theoretical orientation on the part of the observer. Once this thesis is granted, discomfort with hypothetical constructs, intervening variables, mechanisms and the like need no longer dominate concern with the role of linguistic rules in psychology of language. The aim is no longer to make "rule" observational or even operational, but rather to understand its role in the understanding of psychology of language.

Leaving descriptivism behind, we are still not out of the woods. Realism and instrumentalism remain viable alternatives for ways of understanding the role of theories in scientific explanation. On a realist interpretation, theoretical entities may not be observable, but they are nontheless real (e.g., sub-atomic particles are not directly observable, but they are there). It is this sort of interpretation that has led to contentions by psycholinguists that linguistic rules are involved in verbal development and behavior. Certain linguistic rules are required to give an adequate account of verbal behavior. Since the notion of a rule is required for such explanation, there must really be such a rule operating in the development and performance of the speaker/hearer. On my interpretation of $\mathrm{T}-3$, "involvement of a rule" is anomalous for the realist, since I required denying the "reality" of a rule, just where he requires affirming it. Even if my interpretation can be gotten around, the realist still has the problem of telling us just what sort of theoretical reality a rule is. Is it linguistic, psychological, or physiological? Can one or another of these be reduced to another? With these questions we are clearly thrown back upon earlier quandires.

My interpretation of T-3 is clearly instrumental, treating rules as heuristic devices of inquiry for understanding, predicting and planning. The role of rules in explanation are thus seen as the tools of the inquirer, not the referents of the inquiry. This leaves the question of the relations of various concerns of linguistics, psychology and physiology regarding rules still in question. It does, however, show that the question of whether they are related is an open one, and it also shows that the question of whether they are reduceable to one another is an unnecessary one. ${ }^{1}$ But if it so alleviates some of the problems of a realist

\footnotetext{
1 Something of this last point has already been set forth in John Lamendella's contribution to this conference, although we may differ in the details of formulation and implication. An instrumentalist interpretation of theories requires no single understanding of the same objects and events, but allows for a variety of explanations according to a variety of concerns. The realist requires reduction, for economy of inquiry and simplicity of ontology.
} 
interpretation, it brings with it problems of its own. If "involvement of a rule" appears anomalous from a realist perspective, "involvement of a rule" appears mysterious from an instrumentalist perspective. If the notion of a rule is required for explanation of the psychology of linguistic development and performance, to say that it is only required for the understanding of the inquirer seems to deny that he is really getting at what is going on in the speaker/hearer situation. Are rules involved for the actors as well as the spectator? If so, the question of how they are involved remains. That they are involved differently for the actors from their explanatory role for the spectator only accents our earlier quandries about how rules are involved in speaking.

We undertook this exploration of structure/function, competence/performance, and explanation/observation, with the hope that exposition of similarities and relations to rules/ action would also reveal a more adequate understanding of the notion of a rule in psycholin quistic concerns, and with that answers to our earlier questions. What we have found are new questions, many of which seem to be reformulations of the questions exposed in our earlier explorations. Indeed, an adequate exposition of the notion of a rule seems to be required for an adequate understanding of these similarities and relations.

\section{V}

In this paper, I have produced no more than I promised. In exploring the notion of a rule, I have offered a few questions that give some orientation to conceptual problems, and a few theses that give some direction for further exploration. Negatively, we have found that it makes no sense to talk of rules of Language; that there is a shift in roles from rules of language to rules for speaking and that their relationship requires examination; that the notion of a rule is without an established conceptual home within linguistic and psycholinguistic discourse. Positively, I have presented some theses and some explorations of "rulegoverned behavior"t that suggest that an adequate notion of a rule in these contexts must wait upon a more adequate understanding of intentional action. The notion of a rule presents some exciting prospects in these contexts, among them a bridge between the formal and empirical sciences (but unlike engineering) and between the natural and social sciences (but unlike physiological psychology). For such bridges to stand, however, we must understand the notion of a rule on which they are based.

\section{References}

Carnap, Rudolf, (1950), "Empiricism, Semantics, and Ontology", Revue Internationale de Philosophie, 4, 20-41. Reprinted with revisions in his Meaning and Necessity; A study in semantics and modal logic, 2nd Ed., Chicago: University Press (1956) and in Olshewsky, T (ed.), Problems in the Philosophy of Language, New York: Holt, Rinehart and Winston (1969). 
Carnap, Rudolf (1936), "Testability and Meaning", Philosophy of Science, $\underline{3}, 419-471$.

Carnap, Rudolf (1937), "Testability and Meaning", Philosophy of Science, $\underline{4}, 2-40$.

Chomsky, Noam (1961), "On the Notion 'Rule of Grammar' ", Proceedings of the Twelfth Symposium on Applied Mathematics. Reprinted in Fodor, J. A. and J. J. Katz (eds), The Structure of Language; Readings in the philosophy of language, Englewood Cliffs: Prentice-Hall (1964).

Chomsky, Noam (1968), Language and Mind, New York: Harcourt, Brace and World.

Fodor, J. (1966), "How to Learn to Talk: Some Simple Ways", in Smith, F. and G.A. Miller (eds.), The Genesis of Language, a Psycholinguistic Approach, Proceedings of a Confrence on Language Development in Children, Cambridge: MIT Press (1966).

Gumb, Raymond (1972), Rule-governed Linguistic Behavior, The Hague: Mouton.

Hempel, Carl (1965), "Empiricist Criteria of Cognitive Significance", Aspects of Scientific Explanation and Other Essays in the Philosophy of Science, New York: Free Press. Reprinted in Olshewsky, T. (ed.), Problems in the Philosophy of Language, New York: Holt, Rinehart and Winston (1969).

Henley, Kenneth (1969), Rules and Language, Unpublished Master's Thesis, University of Virginia.

McNeill, David (1970), The Acquisition of Language: the Study of Developmental Psycholinguistics, New York: Harper and Row.

Miller, G.A. and S. Isard (1963), "Some Perceptual Consequences of Linguistic Rules", J. Verbal Learning and Verbal Behavior, 2. Reprinted in Jakobovits, L.A. and M. S. Miron (eds.), Readings in the Psychology of Language, Englewood Cliffs: Prentice-Hall (1967).

Quine, Willard (1970), "Methodological Reflections on Current Linguistic Theory", Synthese, 21 .

Saporta, Sol (1967), Psycholinguistic Theories and Generative Grammer, Eugene, Oregon: State System of Higher Education.

Searle, John R. (1969), Speech Acts: An Essay in the Philosaphy of Language, London: Cambridge University Press.

Wittgenstein, Ludwig (1958), Preliminary studies for the "Philosophical Investigations", generally known as the Blue and Brown Books, New York: Harper. 